\title{
袍鸟栖息对杭州湾湿地土壤磷累积及形态分布的影响
}

\author{
赵亦欢 ${ }^{1,2}$, 吴 明 1,2 , 邵学新 ${ }^{1,2, *}$ \\ 1 中国林业科学研究院亚热带林业研究所, 杭州 311400 \\ 2 国家林业和草原局杭州湾湿地生态系统定位观测研究站, 杭州 311400
}

\begin{abstract}
摘要:土壤中磷含量对维持生态系统平衡起着重要作用。为研究杭州湾湿地迁徙候鸟栖息以及鸟粪的输人对栖息地土壤生态 环境的影响,开展了鹭鸟筑巢树林下 (影响区) 和无鹭鸟筑巢树林下 (对照区) 土壤磷累积、土壤及鸟粪磷形态分布研究。结果 表明:鹭鸟影响区土壤有机碳 ( Soil Organic Carbon, SOC)、全氮 ( Total Nitrogen, TN)、全磷 (Total Phosphorus, TP)、有效磷 (Available Phosphorus, AP) 含量显著高于对照区 $(P<0.05)$; 对照区土壤 TP 含量为 $718.33 \mathrm{mg} / \mathrm{kg}$, 影响区土壤 TP 平均含量最高 可达 $2040 \mathrm{mg} / \mathrm{kg}$, 其中钙结合态磷 ( Ca-bound P, Ca-P) 含量最高, 约占 55.22\%-62.96\%, 其次是残渣态磷 (Residual Phosphorus, $\mathrm{RP}$ )、有机磷 (Organic Phosphorus, OP)、铁铝结合态磷 ( Fe/Al-bound P, ( Al+Fe)-P)) 、交换态磷 (Exchangeable P,Exch-P)。鸟 粪中有机碳( Organic Carbon, OC) 、TN、TP 含量分别是表层土壤的 11.18-40.90 倍, 94.22-148.11 倍, 15.41一43.22 倍, 差异极 显著 $(P<0.01)$ 。 TP 含量与 Exch-P、 $(\mathrm{Fe}+\mathrm{Al})-\mathrm{P} 、 \mathrm{Ca}-\mathrm{P} 、 \mathrm{AP}$ 极显著正相关, 与 $\mathrm{RP}$ 显著正相关, 与 $\mathrm{pH}$ 显著负相关。结果表明鸟粪 输人使杭州湾湿地土壤 TP 含量显著提高, Exch-P、 $(\mathrm{Fe}+\mathrm{Al})-\mathrm{P} 、 \mathrm{Ca}-\mathrm{P} 、 \mathrm{AP}$ 含量均有提高, 且占 TP 百分比增大, 鸟粪输人造成了 该地土壤磷素累积的同时增加了土壤磷素的流失风险。
\end{abstract}

关键词: 杭州湾湿地; 鹭鸟栖息; 磷形态;分布

\section{Impact of egrets habitation on accumulation and distribution of various forms of phosphorus in soils of Hangzhou Bay wetland}

\author{
ZHAO Yihuan ${ }^{1,2}$, WU Ming ${ }^{1,2}$, SHAO Xuexin ${ }^{1,2, *}$ \\ 1 Research Institute of Subtropical Forestry, Chinese Academy of Forestry, Hangzhou 311400, China \\ 2 Hangzhou Bay Wetland Ecosystem Research Station of National Forestry and Grassland Bureau, Hangzhou 311400, China
}

\begin{abstract}
The content of phosphorus in soil plays an important role in maintaining the balance of the ecosystem. In order to study the impact of migratory birds inhabiting and dropping guano on the soil ecological environment in Hangzhou Bay wetland, the research of phosphorus accumulation and distribution of various forms of phosphorus in soil and guano was carried out in the area with or without egrets inhabiting ( affected area and controlled area). The results showed that the content of Soil Organic Carbon ( SOC), Total Nitrogen (TN), Total Phosphorus (TP) and Available Phosphorus ( AP) in the egrets effecting area was significantly higher than that in the controlled area $(P<0.05)$. The soil TP content in the controlled area was $718.33 \mathrm{mg} / \mathrm{kg}$, which was up to $2040 \mathrm{mg} / \mathrm{kg}$ in the affected area. The content of Ca-bound P (Ca-P) rank first among all these forms of phosphorus, accounting for about 55.22\%-62.96\%, followed by Residual Phosphorus ( RP) , Organic Phosphorus ( OP ), Fe/Al-bound P ( ( Fe + Al) $-\mathrm{P})$ and Exchangeable P ( Exch-P). The contents of Organic Carbon (OC), TN, and TP in guano were 11.18 - 40.90 times, 94.22-148.11 times and 15.41-43.22 times of the soil, showing significant difference $(P<0.01)$. TP content showed extremely significantly positive correlations with
\end{abstract}

基金项目:国家自然科学基金项目(31870597); 浙江省自然科学基金项目(LY18D010005)

收稿日期:2020-10-19; 采用日期:2021-03-01

* 通讯作者 Corresponding author.E-mail: shaoxuexin@126.com 
Exch-P, ( Fe+Al)-P, Ca-P, AP, significantly positively correlated with RP, while significantly negatively correlated with pH. Generally, the content of TP in soil of Hangzhou Bay wetland was significantly increased due to guano input. The content of Exch-P, $(\mathrm{Fe}+\mathrm{Al})-\mathrm{P}$, Ca-P and AP were all increased, so as the percentages of them did in TP. Input of guano caused the accumulation of phosphorus in the soil which increased the risk of phosphorus loss from the soil, as well.

Key Words : Hangzhou Bay Wetland; egret habitat; phosphorus morphology ; distribution

磷是基本生源要素之一 ${ }^{[1]}$, 由磷导致的水体富营养化也是全球性的环境问题之一。在磷循环过程中,存 在两个局部的小循环, 即陆地生态系统中的磷循环和水生生态系统中的磷循环。这两个小循环之间也存在着 交流,陆地土壤对磷的吸持量存在一定限度, 当磷含量超出这个限度时就会面临流失进人水体的风险。人类 在生产生活过程中会以多种形式向土壤排放磷, 禽畜养殖和农田施肥便是土壤磷的两个重要来源 ${ }^{[2-5]}$ 。 Vervoort 等的研究表明,美国乔治亚州有禽畜粪便施人的土壤磷渗透量大于无禽畜粪便施人的土壤,该地区 地下水的硝酸盐和磷酸盐污染主要来源于禽畜有机肥的使用 ${ }^{[6]}$ 。颜芳等人的研究表明中国设施菜地的磷肥 过度使用导致土壤表层磷素过量累积, AP (有效磷, Available Phosphorus) 含量远远超出损失环境拐点值 ${ }^{[7]}$ 。

水陆生态系统间存在各种物理或者生物的方式驱动着养分的再分配 ${ }^{[8-9]}$ 。风、水等非生物以及植物、鸟 类等种类繁多的生物通过植物和动物的残体、溶解的化合物、土壤颗粒、干沉降和粪便等形式传递营养物 质 ${ }^{[9]}$ 。例如从全球范围来看, 沿海地区每年能接受的来自海岸带的藻类碎屑、残体以及富含氮的海洋泡沫等 有机质约 10-2000 kg/m 海岸线。鱼类的洄游产卵也起着传输营养物质的作用。海鱼捕捞每年传输的磷大

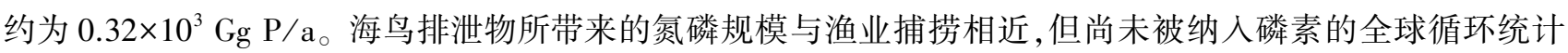
中。目前磷从陆地向水体迁移过程的研究受到较多关注,而磷从水体返回陆地的研究则较为欠缺。

滨海湿地是联系水、陆生态系统的主要通道。杭州湾湿地位于东亚-澳大利西亚迁徙路线的中心位置, 是 迁徙水鸟重要的停歇地和越冬地 ${ }^{[10]}$ 。路鸟是栖息在杭州湾滨海湿地的主要鸟类,位于食物链的顶端, 具有集

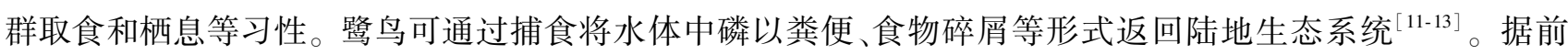
期调查,杭州湾湿地公园栖息水鸟约有 12000 只,鸟巢约 6000 个,大量的鸟粪输人会给杭州湾土壤磷累积情 况造成什么影响目前尚不明确。土壤中磷元素有多种存在形式,不同的存在形式直接影响磷的生物有效性, 以及植物的生产水平 ${ }^{[14]}$ 。因此, 为研究杭州湾湿地迁徙候鸟栖息以及鸟粪的输人对该土壤生态环境的影响, 开展了对鹭鸟筑巢树林下和对照区土壤磷累积状况及形态分布的研究。

\section{1 材料与方法}

\section{1 研究区概况}

研究区位于浙江杭州湾国家湿地公园内 (图 1)。该区域属庵东沼泽区国家重要湿地, 是我国东部大陆海 岸冬季水鸟最富集的地区之一, 也是东亚一澳大利西亚候鸟迁徙路线中的重要驿站, 主要由自然滩涂和围怎 湿地 (草本沼泽、芦苇水塘及有林湿地) 等景观构成。有林湿地位于湿地公园东南角, 区块地势平坦, 本底条 件一致, 土壤为滨海盐土, 质地为粉砂质, 是 2004-2005 年于围怎初期营建的滨海滩涂树种试验林, 主要用于 滨海围层区及防护林带适生树种篮选试验, 后开展湿地恢复项目, 于林地内人工开挖水系, 改造为有林湿地区 域。研究区路类主要在滩涂、沼泽等取食, 然后栖息和营巢于有林湿地区块。

1.2 样地设置及样品采集

根据国家林业和草原局杭州湾湿地生态系统定位观测研究站的长期定位观测资料,鹭类繁殖区位于湿地 公园的有林湿地区块, 该区块由人工林改造而来, 总面积约 $40 \mathrm{hm}^{2}$, 区块内路鸟筑巢栖息的主要树种为水杉 (Metasequoia glyptostroboides) 和女贞 (Ligustrum lucidum)。以有无鹗鸟筑巢为依据, 分别在以上两个树种试验 林中设置路鸟栖息繁殖区 (影响区) 及其无鹭鸟栖息区域 (对照区)。对照区域邻近鹭鸟影响区, 相距约 


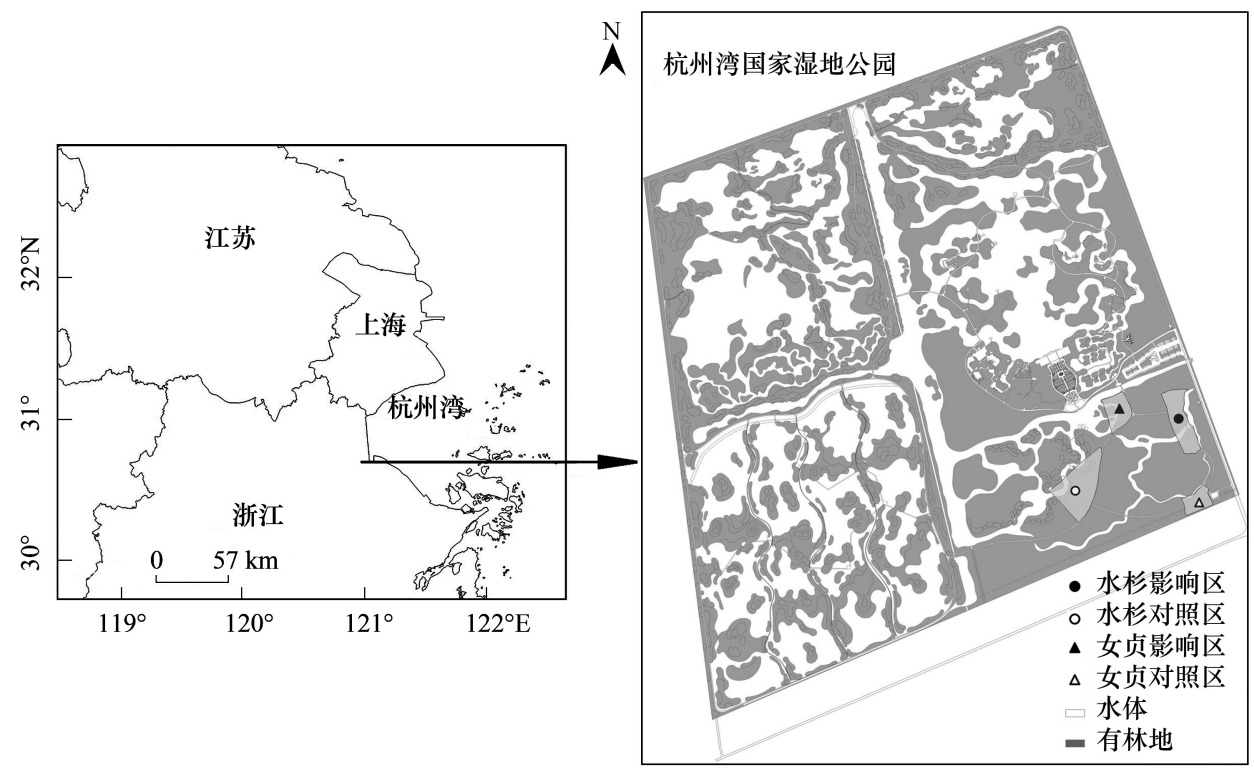

图 1 采样点分布图

Fig.1 Spatial distribution maps about sampling points

$200 \mathrm{~m}$ 。对照区水鸟活动极少的原因是其靠近游步道等人为干扰频繁的区域,而鸟类对人为活动非常敏感。 在上述区域分别设置 $20 \mathrm{~m} \times 20 \mathrm{~m}$ 的影响区样地和对照区样地各 3 处。本实验于 2018 年 11 月 (繁殖栖息结束 后), 采集研究区土壤样本。野外每个样地内按对角线法取样, 采用环状取样器采集 0-10 $\mathrm{cm}$ 与 $10-20 \mathrm{~cm}$ 深的土壤剖面样品, 采回的土壤样品冷冻干燥, 研磨后过笁保存。采用样地随机预先铺设塑料薄膜收集的方 法采集繁殖期鸟类粪便,将粪便风干研磨后过篮保存。

\section{2 实验方法}

\section{1 基本指标测定}

采集的土壤和鸟粪样品测定土壤有机碳 (Soil Organic Carbon, SOC)、全氮 (Total Nitrogen, TN)、全磷 (Total Phosphorus, TP)、pH 值、电导率等基本理化性质, 具体测定方法参考《土壤农业化学分析方法》 ${ }^{[15]}$, 有 效磷( Available Phosphorus, AP) 采用碳酸氢钠法提取。

\section{2 磷形态测定}

土壤和鸟粪磷素化学形态采用改进的 Hieltjes \& Lijkema 连续提取方法。分别提取可交换态磷 (Exchangeable P, Exch-P)、铁铝结合态磷 $(\mathrm{Fe} / \mathrm{Al}$-bound P, $(\mathrm{Al}+\mathrm{Fe})-\mathrm{P}) 、$ 、钙结合态磷 $(\mathrm{Ca}-$-bound P, Ca-P) 和有 机磷 (Organic Phosphorus, OP)。提取方法:采用高氯酸-硫酸消煮法提取 TP; 使用 $2 \mathrm{~mol} / \mathrm{L} \mathrm{KCl}$, 振荡 $2 \mathrm{~h}$ 提取 Exch-P ; 加人 $0.1 \mathrm{~mol} / \mathrm{L}$ 的 $\mathrm{NaOH}$ 溶液, 振荡 $17 \mathrm{~h}$ 提取 $(\mathrm{Fe}+\mathrm{Al}$ ) - P ; 用饱和 $\mathrm{NaCl}$ 溶液洗涤上步残渣后, 加人 0.5 $\mathrm{mol} / \mathrm{L}$ 的 $\mathrm{HCl}$ 溶液振荡 $24 \mathrm{~h}$ 提取 Ca-P; 另称取两份等量样品, 其中一份 $550^{\circ} \mathrm{C}$ 灼烧 $2 \mathrm{~h}$, 两份均加人 $0.1 \mathrm{~mol} / \mathrm{L}$ 的 $\mathrm{H}_{2} \mathrm{SO}_{4}$ 溶液, $40^{\circ} \mathrm{C}$ 环境下振荡 $1 \mathrm{~h}$ 提取 $\mathrm{OP}$ 。提取液用磷钿蓝分光光度法测定相应的磷含量, 用测得的 $\mathrm{TP}$

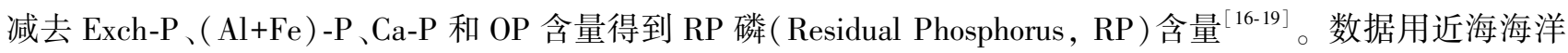
沉积物成分分析标准( GBW 07314) 进行校正比对分析。

\section{3 统计分析}

用 SAS V8 的 CORR 程序对实验数据进行方差分析, 并对 SOC、TN、TP、AP 含量、电导率、 $\mathrm{pH}$ 值、Exch-P、 $(\mathrm{Fe}+\mathrm{Al})-\mathrm{P} 、 \mathrm{Ca}-\mathrm{P} 、 \mathrm{OP} 、 \mathrm{RP}$ 含量进行相关性分析, 用 Duncan 法对每个指标的实验数据进行多重比较。 


\section{3 结果分析}

\section{1 基本理化性质分析}

如图 2 所示,女贞影响区表层土壤 SOC 含量最高 $(13.71 \mathrm{~g} / \mathrm{kg})$, 其次为水杉影响区表层 $(9.22 \mathrm{~g} / \mathrm{kg})$; 女贞 和水杉影响区表层土壤 SOC 含量是底层土壤的 2.1 和 2.8 倍, 差异显著 $(P<0.05)$; 两树种影响区土壤表层 SOC 分别是对照区的 2.5 和 1.9 倍, 差异显著 $(P<0.05)$ 。土壤 TN 含量最高的是女贞影响区表层 $(1.45$ $\mathrm{g} / \mathrm{kg})$, 其次是水杉影响区表层 $(1.04 \mathrm{~g} / \mathrm{kg})$, 分别是底层的 2.5 和 5.2 倍, 差异显著 $(P<0.05)$; 两树种影响区土 壤表层 TN 分别是对照区的 1.1 和 1.6 倍, 差异显著 $(P<0.05)$ 。水杉影响区表层土壤的 TP 含量最高 $(2.04$ $\mathrm{g} / \mathrm{kg})$, 显著高于 $(P<0.05)$ 女贞影响区表层 $(1.60 \mathrm{~g} / \mathrm{kg})$; 水杉和女贞影响区表层土壤 TP 含量分别是底层土壤 的 1.8 和 1.9 倍, 差异显著 $(P<0.05)$; 影响区表层与对照区表层差异显著 $(P<0.05)$, 对照区表层土壤 TP 含量 大于底层, 但差异不显著 $(P>0.05)$ 。土壤 $\mathrm{AP}$ 含量最高的是水杉影响区表层 $(106.00 \mathrm{~g} / \mathrm{kg})$, 其次是女贞影响
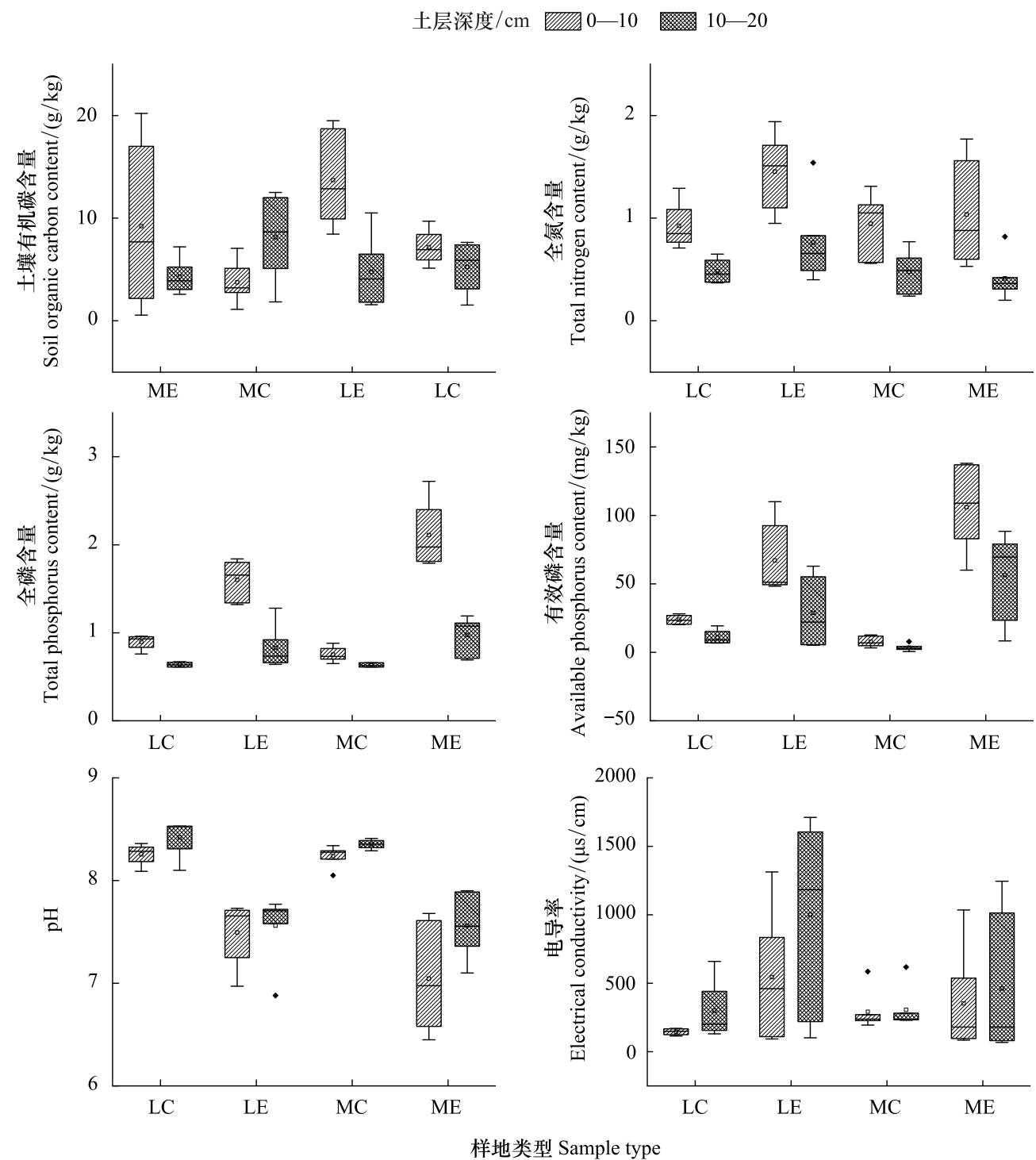

图 2 杭州湾湿地土壤基本理化性质

Fig.2 Basic physical and chemical properties of soil in Hangzhou Bay Wetland

ME,水杉影响区 Metasequoia glyptostroboides Egrets plot; MC, 水杉对照区 Metasequoia glyptostroboides Control plot; LE, 女贞影响区 Ligustrum lucidum Egrets plot; LC, 女贞对照区 Ligustrum lucidum Control plot 
区表层 $(67.80 \mathrm{~g} / \mathrm{kg})$, 两树种影响区表层 AP 含量是底层的 2.5 和 2.9 倍,差异显著 $(P<0.05)$; 水杉和女贞影 响区表层 AP 含量是对照区的 13.7 倍和 2.8 倍, 差异显著 $(P<0.05)$; 水杉影响区表层 AP 含量显著高于女贞 影响区表层。女贞和水杉影响区土壤 $\mathrm{pH}$ 值显著低于对照区。土壤 EC 表现为影响区高于对照区,水杉影响 区表层和底层分别是对照区的 1.2 倍和 1.5 倍, 差异不显著 $(P>0.05)$, 女贞影响区表层和底层分别是对照区 的的 3.8 倍和 1.9 倍, 差异显著 $(P<0.05)$; 女贞影响区与水杉影响区差异显著 $(P<0.05)$ 。

\section{2 磷形态分布}

根据磷形态测定结果 (如图 3) , 水杉影响区表层土壤的 TP 含量最高 $(2040.00 \mathrm{mg} / \mathrm{kg})$, 显著高于 $(P<$ $0.05)$ 女贞影响区表层 $(1601.67 \mathrm{mg} / \mathrm{kg})$; 水杉和女贞影响区表层土壤 TP 含量分别是底层土壤的 1.8 和 1.9 倍, 差异显著 $(P<0.05)$; 对照区平均 TP 含量为 $718.33 \mathrm{mg} / \mathrm{kg}$, 影响区表层与对照区表层差异显著 $(P<0.05)$, 对照区表层土壤 TP 含量大于底层, 但差异不显著 $(P>0.05)$ 。女贞影响区表层土壤中 Exch-P 含量最高 $(3.78$ $\mathrm{mg} / \mathrm{kg})$, 是水杉影响区表层土壤的 1.4 倍, 但差异不显著 $(P>0.05)$; 女贞和水杉影响区表层土壤 Exch-P 含量 分别是底层土壤的 1.4 和 1.2 倍, 差异显著 $(P<0.05)$; 影响区 Exch-P 含量是对照区的 4 倍以上, 差异显著 $(P<$ $0.05)$; 对照区不同深度土壤 Exch-P 含量无显著差异。水杉影响区表层土壤 $(\mathrm{Fe}+\mathrm{Al})-\mathrm{P}$ 含量最高 ( 132.97 $\mathrm{mg} / \mathrm{kg}$ ), 显著高于女贞影响区表层土壤 $(40.70 \mathrm{mg} / \mathrm{kg}$ ) ; 水杉和女贞影响区表层土壤 ( $\mathrm{Fe}+\mathrm{Al}$ ) $-\mathrm{P}$ 含量分别是底

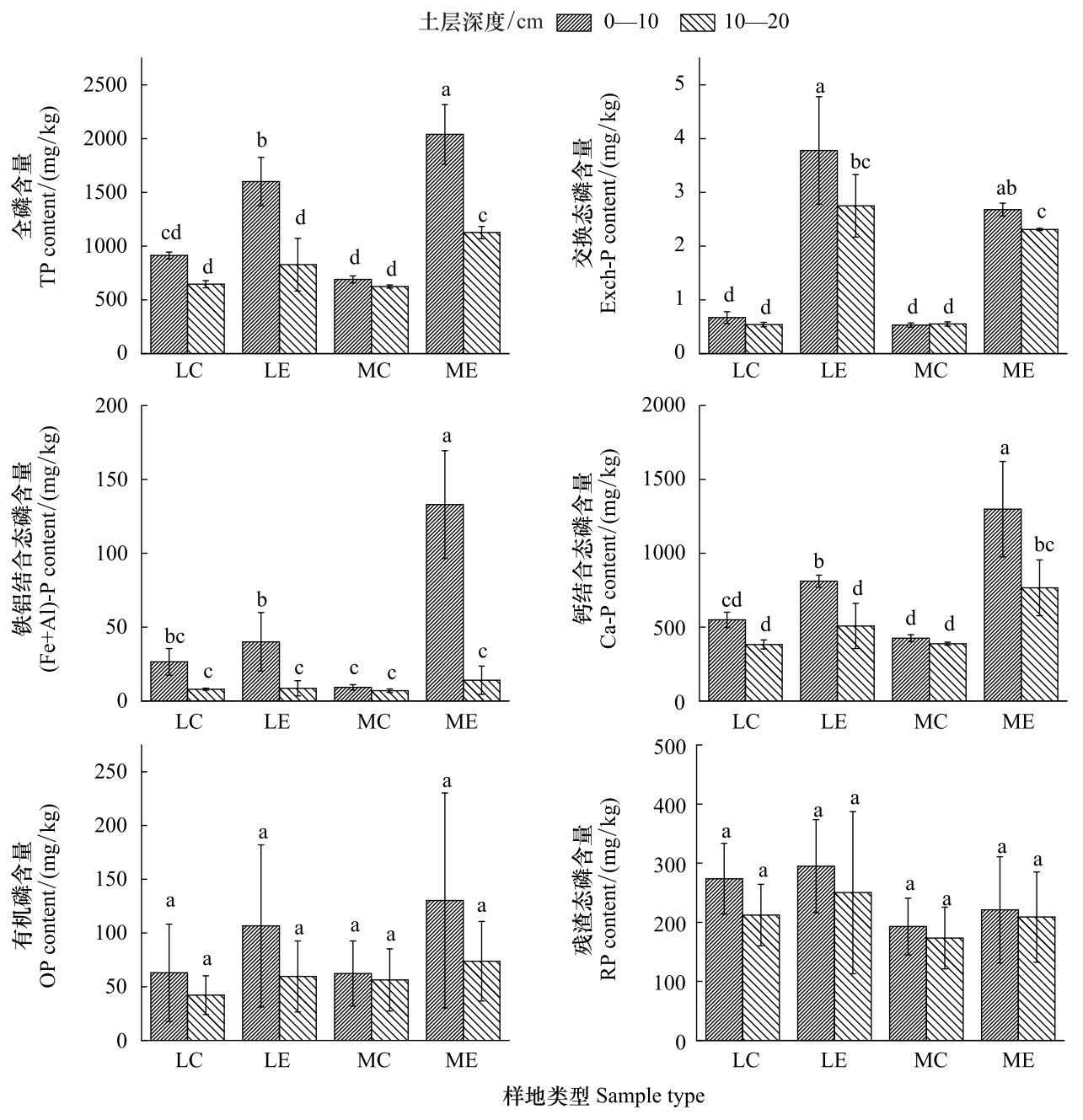

图 3 不同深度不同树种土壤磷形态分布图

Fig.3 Soil phosphorus distribution patterns of different tree species at different depths

不同小写字母表示在 $P=0.05$ ( Duncan 检验) 显著性水平差异 
层土壤的 9.4 和 4.7 倍, 差异显著 $(P<0.05)$; 两树种影响区底层土壤与对照区表层和底层土壤差异不显著, 表 明鸟粪输人提高了表层土壤的 $(\mathrm{Fe}+\mathrm{Al})-\mathrm{P}$ 。水杉影响区表层 $\mathrm{Ca}-\mathrm{P}$ 含量最高 $(1298.33 \mathrm{mg} / \mathrm{kg})$, 是女贞影响区 表层土壤 $(811.25 \mathrm{mg} / \mathrm{kg})$ 的 1.6 倍, 差异显著 $(P<0.05)$; 水杉和女贞影响区表层土壤 Ca-P 含量分别是底层土 壤的 1.7 和 1.6 倍, 差异显著 $(P<0.05)$; 对照区表层土壤 Ca-P 含量为 $425.42 \mathrm{mg} / \mathrm{kg} 、 549.17 \mathrm{mg} / \mathrm{kg}$, 与影响区有 显著差异, 底层土壤差异不显著, 表明鸟粪输入提高了表层土壤的 $\mathrm{Ca}-\mathrm{P}$ 。水杉影响区表层 OP 含量最高 $(130.25 \mathrm{mg} / \mathrm{kg})$, 女贞影响区表层次之 $(106.60 \mathrm{mg} / \mathrm{kg})$, 水杉和女贞影响区表层土壤 OP 含量分别是底层的 1.7 和 1.8 倍, 但离散程度较大, 差异不明显 $(P>0.05)$; 水杉和女贞影响区表层土壤 $\mathrm{OP}$ 分别是对照区的 2.1 和 1.7 倍。两树种影响区和对照区不同深度 RP 含量为 $173.34-294.87 \mathrm{mg} / \mathrm{kg}$, 差异不显著。

不同深度土壤影响区 Exch-P、 $(\mathrm{Fe}+\mathrm{Al})-\mathrm{P} 、 \mathrm{Ca}-\mathrm{P} 、 \mathrm{OP}$ 和 RP 占 TP 的百分比(如图 3 ) 分别为 $0.13 \%-$ $0.18 \% 、 1.25 \%-4.18 \% 、 55.22 \%-62.96 \% 、 6.38 \%-7.94 \%$ 和 $27.66 \%-34.08 \%$, 对照区分别占 $0.07 \%-0.09 \%$ 、 $1.16 \%-2.23 \% 、 60.63 \%-60.78 \% 、 7.76 \%-7.82 \%$ 和 $29.10 \%-30.56 \%$ 。水杉和女贞影响区 Ca-P 所占百分比 表层相比对照区高出 $14 \%$ 和 $4 \%$, 底层相比对照区分别高出 $7 \%$ 和 $2 \%$ 。

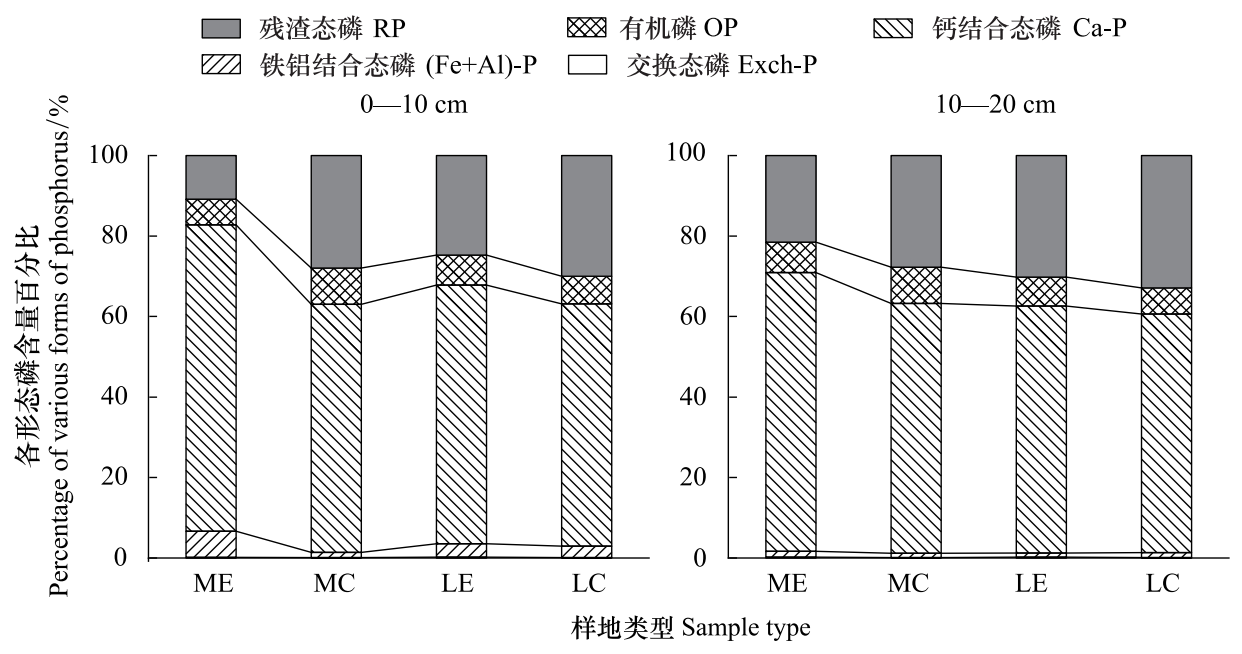

图 4 各形态磷占 TP 百分比

Fig.4 Percentage of phosphorus in all forms

3.4 鸟粪碳氮磷含量及磷形态分布

如图 5 所示, 鸟粪中 OC 含量为 $153.25 \mathrm{~g} / \mathrm{kg}$, 分别是水杉影响区 $(9.22 \mathrm{~g} / \mathrm{kg})$ 和对照区 $(3.75 \mathrm{~g} / \mathrm{kg})$ 表层土 壤的 16.6 和 40.9 倍, 女贞影响区 $(13.71 \mathrm{~g} / \mathrm{kg})$ 和对照区 $(7.17 \mathrm{~g} / \mathrm{kg})$ 表层土壤的 11.2 和 21.4 倍, 差异极显著 $(P<0.001)$; 鸟粪中 TN 含量为 $137.00 \mathrm{~g} / \mathrm{kg}$, 分别是水杉影响区 $(1.04 \mathrm{~g} / \mathrm{kg})$ 和对照区 $(0.94 \mathrm{~g} / \mathrm{kg})$ 表层土壤的 131.7 和 145.7 倍, 女贞影响区 $(1.45 \mathrm{~g} / \mathrm{kg})$ 和对照区 $(0.93 \mathrm{~g} / \mathrm{kg})$ 表层土壤的 94.5 和 147.3 倍, 差异极显著 $(P<$ $0.001)$; 鸟粪中 TP 含量为 $32.55 \mathrm{~g} / \mathrm{kg}$, 分别是水杉影响区 $(2.11 \mathrm{~g} / \mathrm{kg})$ 和对照区 $(0.75 \mathrm{~g} / \mathrm{kg})$ 表层土壤的 15.4 倍和 43.4 倍, 女贞影响区 $(1.60 \mathrm{~g} / \mathrm{kg})$ 和对照区 $(0.90 \mathrm{~g} / \mathrm{kg})$ 表层土壤的 20.3 倍和 36.2 倍, 差异极显著 $(P<$ 0.001 )。

对鸟粪磷形态分级测定表明, 鸟粪中 Exch-P 含量为 $(2.75 \pm 0.2) \mathrm{mg} / \mathrm{kg}$, 是土壤的 $727.5-5213.7$ 倍。 $(\mathrm{Fe}+\mathrm{Al})-\mathrm{P}$ 含量为 $(0.57 \pm 0.39) \mathrm{mg} / \mathrm{g}$, 是土壤的 $4.29-82.31$ 倍。Ca-P 含量为 $(5.20 \pm 1.26) \mathrm{mg} / \mathrm{g}$, 是土壤的 $4.0-13.6$ 倍。 $\mathrm{OP}$ 含量为 $(2.93 \pm 0.93) \mathrm{mg} / \mathrm{g}$, 是土壤的 $22.5-69.4$ 倍。 $\mathrm{RP}$ 含量为 $(21.1 \pm 4.18) \mathrm{mg} / \mathrm{g}$, 是土壤 的 30.0-121.8 倍。鸟粪中 RP 在五种形态磷中所占比例最高, 与土壤中 Ca-P 占比最高不同, Exch-P 含量在 鸟粪中与土壤中差异最大。

\section{4 相关性分析}

对影响区和对照区土壤基本性质及磷形态的相关性分析表明(表 1), 对照区 TP 与 Exch-P、( Fe+Al) -P、 

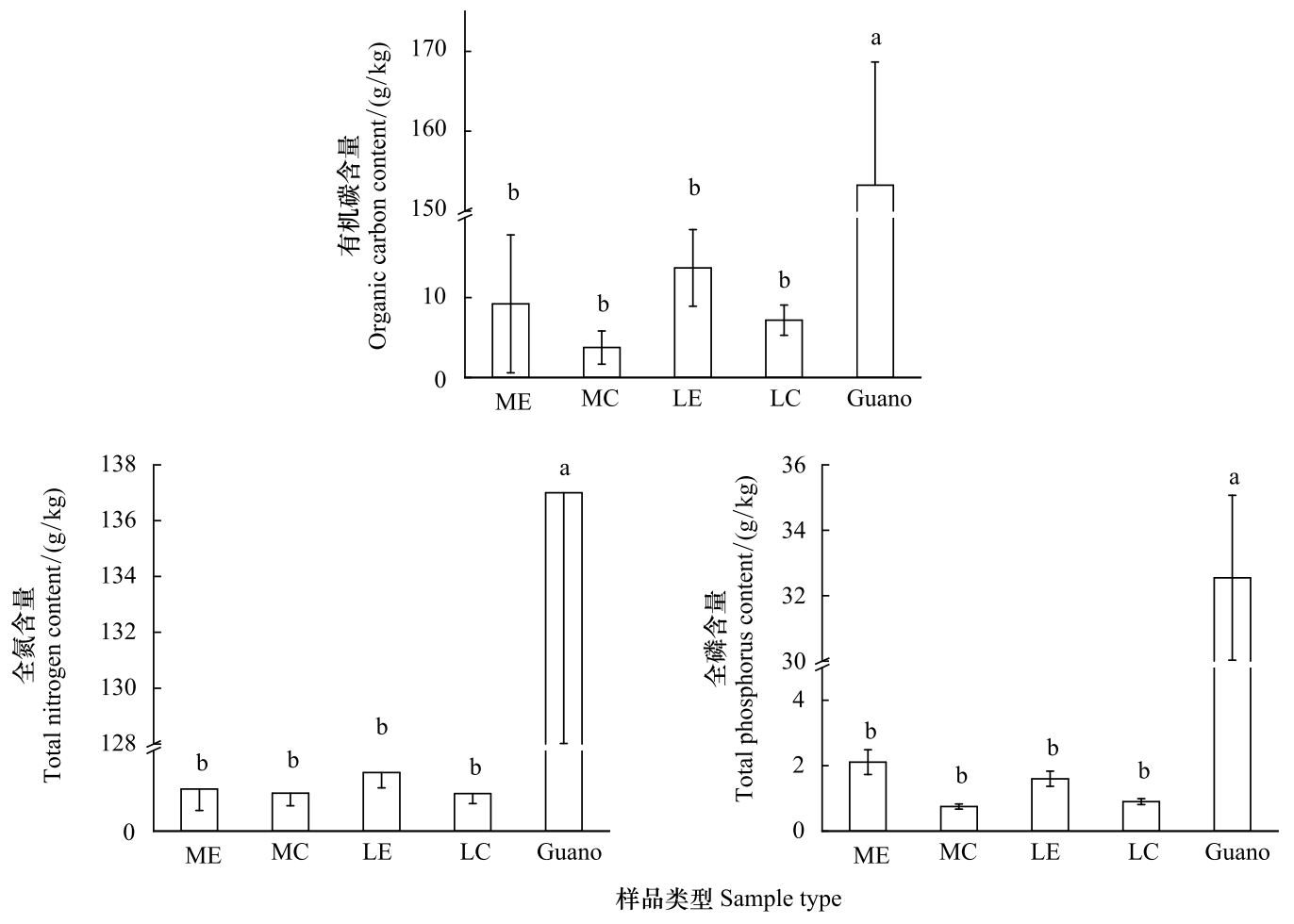

图 5 乌粪与土壤中的碳氮磷含量

Fig.5 Content of carbon, nitrogen and phosphorus in guano and soil

不同小写字母表示在 $P=0.05$ ( Duncan 检验) 显著性水平差异

Ca-P、AP 极显著正相关 $(R=0.78 、 0.90 、 0.92 、 0.79, P<0.01)$,与 RP 显著正相关 $(R=0.64, P<0.05)$, 表明 Exch$\mathrm{P} 、(\mathrm{Fe}+\mathrm{Al})-\mathrm{P} 、 \mathrm{Ca}-\mathrm{P} 、 \mathrm{RP} 、 \mathrm{AP}$ 都是对照区土壤磷的重要来源。对照区 $\mathrm{TP}$ 与 $\mathrm{pH}$ 相关性不显著而影响区 $\mathrm{TP}$ 与 $\mathrm{pH}$ 呈显著负相关 $(R=-0.53, P<0.05)$, 表明鸟粪输人提高了土壤磷含量的同时显著降低了土壤 $\mathrm{pH}$ 值。对照 区和影响区内 Exch-P 与 Ca-P 含量相关性表现为极显著 $(R=0.76, P<0.01)$ 和显著 $(R=0.56, P<0.05)$, 表明杭 州湾湿地土壤中 Exch-P 与 Ca-P 存在趋同性。影响区 OP 与 Exch-P 相关性显著 $(R=0.47, P<0.05)$, 而对照区 相关性不明显, 表明鸟粪输人提高了两者的相关性。AP 在影响区和对照区均与 Exch-P、( Fe+Al) -P、Ca-P 极 显著相关 $(P<0.01)$ 。影响区 $\mathrm{pH}$ 与 TP、Exch-P、 $(\mathrm{Fe}+\mathrm{Al})-\mathrm{P} 、 \mathrm{Ca}-\mathrm{P} 、 \mathrm{AP}$ 均呈显著或极显著负相关, 而对照区相 关性不显著, 表明鸟粪输人使得各形态磷含量均有提高, 并降低了土壤的 $\mathrm{pH}$ 值。AP 与 $\mathrm{EC}$ 在影响区和对照 区都呈现极显著负相关 $(R=-0.73 、-0.80, P<0.01)$ 。

\section{4 讨论}

杭州湾湿地土壤由滨海滩涂围筀而来, 呈碱性到弱碱性。无鸟粪影响地区平均氮含量为 $0.67 \mathrm{~g} / \mathrm{kg}$, 土壤 较为肥沃, 在有鸟粪影响的地区平均氮含量为 $0.87 \mathrm{~g} / \mathrm{kg}$, 影响区表层土壤的 SOC、TN、TP、AP 含量高于对照区 表层, 表明鸟粪对该地土壤的养分累积做出了一定贡献。女贞影响区的电导率显著高于其他区域,可能与该 区域靠近主河道,地下水位较高, 导致土壤返盐。

文献表明, 我国土壤表层磷含量为 $0.2-1.1 \mathrm{~g} / \mathrm{kg}^{[20]}$, 杭州湾自然滩涂及其不同围剭年代土壤表层磷含量 为 $0.4-1.0 \mathrm{~g} / \mathrm{kg}^{[21]}$ 。本研究对照区土壤磷含量处于上述平均水平范围内, 但影响区土壤中磷含量均高于平 均值且极显著高于对照区, 说明鸟粪施人造成了土壤磷的累积。水杉林下土壤中磷含量略高于女贞林, 这可 能与鹭鸟的筑巢密度有关。根据 2018 年 7 月的调查数据, 每平方米水杉林内有 0.25 个鸟巢, 大于女贞林的 每平方米 0.16 个鸟巢。影响区和对照区表层土壤磷含量均大于底层土壤, 变异程度大于底层土壤, 且影响区 
变异程度大于对照区,这可能与鹭鸟筑巢的随机性和离散性导致土壤鸟粪输人的不均一性有关。此外,也可 能是因为表层土壤中枯枝落叶腐解等输人量的不均一。

表 1 磷形态及基本参数相关性矩阵

Table 1 Correlation matrix of soil phosphorus forms and basic parameters

\begin{tabular}{|c|c|c|c|c|c|c|c|c|c|c|c|c|}
\hline & & $\mathrm{TP}$ & Exch-P ( & $(\mathrm{Fe} / \mathrm{Al})-\mathrm{P}$ & $\mathrm{Ca}-\mathrm{P}$ & $\mathrm{OP}$ & $\mathrm{RP}$ & SOC & $\mathrm{TN}$ & $\mathrm{AP}$ & $\mathrm{pH}$ & EC \\
\hline 影响区 & $\mathrm{TP}$ & 1 & & & & & & & & & & \\
\hline \multirow[t]{10}{*}{ Egrets plot } & Exch-P & 0.41 & 1 & & & & & & & & & \\
\hline & $(\mathrm{Fe} / \mathrm{Al})-\mathrm{P}$ & $0.84^{* *}$ & 0.30 & 1 & & & & & & & & \\
\hline & Ca-P & $0.76^{* *}$ & $0.56^{*}$ & $0.70^{* *}$ & 1 & & & & & & & \\
\hline & $\mathrm{OP}$ & 0.33 & $0.47^{*}$ & 0.34 & 0.29 & 1 & & & & & & \\
\hline & RP & 0.37 & 0.05 & -0.03 & -0.08 & 0.09 & 1 & & & & & \\
\hline & SOC & 0.42 & -0.32 & 0.11 & -0.14 & -0.18 & $0.77 * *$ & 1 & & & & \\
\hline & $\mathrm{TN}$ & 0.44 & -0.22 & 0.16 & -0.03 & -0.14 & $0.72 * *$ & $0.91^{* *}$ & 1 & & & \\
\hline & $\mathrm{AP}$ & $0.70^{* *}$ & $0.67^{* *}$ & $0.67^{* * *}$ & $0.82^{* * *}$ & 0.41 & 0.02 & -0.19 & -0.15 & 1 & & \\
\hline & $\mathrm{pH}$ & $-0.53^{*}$ & $-0.73^{* *}$ & $-0.53^{*}$ & $-0.80^{* * *}$ & $-0.58^{* * *}$ & 0.09 & 0.35 & 0.21 & $-0.77^{* * *}$ & 1 & \\
\hline & EC & -0.33 & $-0.67^{\text {** }}$ & -0.33 & $-0.52^{*}$ & -0.18 & 0.14 & 0.36 & 0.39 & $-0.73^{* *}$ & 0.43 & 1 \\
\hline 对照区 & Exch-P & $0.78^{* *}$ & 1 & & & & & & & & & \\
\hline \multirow[t]{9}{*}{ Control plot } & $(\mathrm{Fe} / \mathrm{Al})-\mathrm{P}$ & $0.90^{* *}$ & $0.82 * *$ & 1 & & & & & & & & \\
\hline & Ca-P & $0.92^{* *}$ & $0.76^{* *}$ & $0.93^{* * *}$ & 1 & & & & & & & \\
\hline & $\mathrm{OP}$ & 0.21 & 0.25 & 0.16 & 0.28 & 1 & & & & & & \\
\hline & $\mathrm{RP}$ & $0.64^{*}$ & 0.39 & 0.44 & 0.35 & -0.43 & 1 & & & & & \\
\hline & SOC & 0.12 & 0.4 & 0.21 & 0.09 & 0.48 & -0.13 & 1 & & & & \\
\hline & $\mathrm{TN}$ & $0.87^{* *}$ & $0.65 *$ & $0.70^{*}$ & $0.72^{* *}$ & 0.22 & $0.64^{*}$ & 0.09 & 1 & & & \\
\hline & $\mathrm{AP}$ & $0.79^{* *}$ & $0.79^{* *}$ & $0.85^{* * *}$ & $0.73^{* *}$ & 0.04 & 0.53 & 0.11 & $0.65^{*}$ & 1 & & \\
\hline & $\mathrm{pH}$ & -0.23 & -0.03 & -0.15 & -0.23 & -0.11 & -0.11 & 0.05 & -0.38 & 0.15 & 1 & \\
\hline & $\mathrm{EC}$ & -0.54 & $-0.74^{\text {** }}$ & -0.51 & -0.47 & -0.20 & -0.33 & -0.24 & -0.51 & $-0.80^{* * *}$ & -0.22 & 1 \\
\hline
\end{tabular}

$* P<0.05, * * P<0.01$; TP, Total Phosphorus 全磷; Exch-P, 交换态磷 Exchangeable P; ( Al+Fe)-P, 铁铝结合态磷 Fe/Al-bound P; Ca-P : 钙结合态磷 Ca-bound P; OP: 有机磷 Organic Phosphorus; RP: 残渣态磷 Residual Phosphorus; SOC: 土壤有机碳 Soil Organic Carbon; TN: 全氮 Total Nitrogen; AP: 有效磷 Available Phosphorus; $\mathrm{pH}$ : 酸醎度; EC: 电导率 Electric Conductivity

杭州湾湿地土壤磷的存在形式以无机磷为主, 占总磷的 89\%-91\%,其中 Ca-P 磷含量最高, 占无机磷的 93\%- $96 \%$,这与杭州湾滨海湿地土壤的 $\mathrm{pH}$ 有关, 弱碱性土壤使铁铝形成氢氧化物发生沉淀,减少了 $(\mathrm{Fe}+$ $\mathrm{Al}$ ) -P 的产生, 增加了磷酸钲盐的含量 ${ }^{[22-24]}$ 。且研究区位于副热带季风气候区 ${ }^{[25]}$, 高温多雨的气候加速了鹭 鸟粪便的分解形成磷酸盐 ${ }^{[26]}$, 通过矿化作用转变成磷酸钙盐在土壤中大量累积。安婉丽等对闽江口湿地的 研究表明, 土壤 TP 含量为 500-820 mg/ $\mathrm{kg}$, 无机磷占 TP 比例约为 $60 \%-78 \%$, Ca-P 占 TP 比例约为 $23 \%-$ $28 \%{ }^{[27]}$ 。杭州湾湿地与闽江口湿地拥有相似的气候条件和土壤类型, 但杭州湾湿地土壤磷含量高于闽江口 湿地, 无机磷和 Ca-P 占 TP 比例也远高于闽江口湿地, 进一步说明了鸟粪输入影响了土壤磷累积及形态分 布。Marta Ziółek 等对斯匹次卑尔根岛西部海岸的研究结果也表明, 土壤磷分布受海鸟群落影响, 且随着与海 鸟群落距离的改变发生明显变化 ${ }^{[28]}$ 。

$\mathrm{TP}$ 含量与 $(\mathrm{Fe}+\mathrm{Al})-\mathrm{P} 、 \mathrm{Ca}-\mathrm{P}$ 含量均呈极显著正相关, $\mathrm{Ca}-\mathrm{P}$ 与 $(\mathrm{Fe}+\mathrm{Al})-\mathrm{P} 、$ Exch-P 极显著正相关, 可能是由 于该地碱性的土壤环境使得 Exch-P 和 $(\mathrm{Fe}+\mathrm{Al})-\mathrm{P}$ 更易向稳定的磷酸钙盐转化。影响区 $\mathrm{pH}$ 与 AP 呈极显著 负相关而对照区相关性不显著, 这可能是由于鸟粪中含有大量尿酸有关。鸟粪的输人在降低了土壤 $\mathrm{pH}$ 值的 同时提高了土壤 AP 含量。根据影响区和对照区实验结果, 鸟粪输人使影响区土壤 TP 含量增加 $526.33 \mathrm{mg} /$ $\mathrm{kg}$, 增幅达 $73.27 \%$, 影响区 AP 含量比对照区平均增加 $46.69 \mathrm{mg} / \mathrm{kg}$, 占 TP 的比例上升 $6.53 \%, \mathrm{AP}$ 的增加可能 会增加土壤磷流失风险 ${ }^{[29-30]}$ 。受鸟粪影响, 相比对照区, 影响区土壤 $(\mathrm{Fe}+\mathrm{Al})-\mathrm{P} 、 \mathrm{Ca}-\mathrm{P} 、$ Exch-P 含量占 TP 的 比例分别有不同程度的提高, $\mathrm{OP} 、 \mathrm{RP}$ 含量占 $\mathrm{TP}$ 比例略有下降。鸟粪中 Exch-P、 $(\mathrm{Fe}+\mathrm{Al})-\mathrm{P} 、 \mathrm{Ca}-\mathrm{P} 、 \mathrm{OP}$ 含量是 
土壤的数倍到数千倍, 并造成了影响区和对照区 Exch-P 和 Ca-P 含量差异显著。各形态磷中增加最多的是 $\mathrm{Ca}-\mathrm{P}$, 表明鸟粪输人会显著提高土壤磷酸钙盐的含量。鸟粪中大量的 Exch-P 进人当地石灰性土壤后易与土 壤中的钙结合,进一步提高 Ca-P 的含量。磷酸钙盐主要由氟磷灰石、氢氧磷灰石和碳酸磷灰石组成,有效性 低,不能被植物直接利用, 从而慢慢在土壤中累积。

由磷素累积导致的水体富营养化已经成为全球环境问题的热点之一,为此不少学者针对磷流失方式展开 了研究。土壤磷素的流失往往伴随在地表径流和淋溶的过程中。孙海栓等对农田径流的测量发现颗粒态磷 是主要的流失形态, 占流失 TP 量的 $61.6 \%-83.1 \%$; Sharpley 等人通过室内模拟实验发现, 土壤水溶性磷含量 与土壤淋洗液中磷的含量密切相关 ${ }^{[31]}$ 。杭州湾湿地气候湿润多雨, 使路鸟影响区土壤中累积的磷酸钲盐颗 粒和溶解态磷更有可能随径流和淋溶流失。因此对杭州湾湿地土壤磷素流失风险的评估变得尤为重要。

\section{5 结论}

杭州湾湿地土壤磷含量表现为鹭鸟影响区显著高于对照区, 影响区表层土壤磷含量也显著高于底层, 说 明鹭鸟栖息导致的鸟粪输人造成了土壤磷的累积。研究区土壤磷的主要赋存形式为 Ca-P, 土壤 TP 及 AP 含 量与 Exch-P、( Fe+Al) -P、Ca-P 显著正相关。由于鹭鸟栖息下土壤 Exch-P、 $(\mathrm{Fe}+\mathrm{Al})-\mathrm{P} 、 \mathrm{Ca}-\mathrm{P}$ 含量及其比例相 比对照区均显著提高, 因此,土壤 TP 特别是 AP 含量的提高可能导致湿地土壤磷素流失风险的增加。

\section{参考文献 ( References) :}

[ 1 ] Liu X, Sheng H, Jiang S Y, Yuan Z W, Zhang C S, Elser J J. Intensification of phosphorus cycling in China since the 1600s. Proceedings of the National Academy of Sciences of the United States of America, 2016, 113(10): 2609-2614.

[ 2 ] 曾悦, 洪华生, 陈伟其, 郑或. 畜禽养殖区磷流失对水环境的影响及其防治措施. 农村生态环境, 2004, 20(3): 77-80.

[ 3 ] 赵亚杰, 赵牧秋, 鲁彩艳, 史奕, 陈欣. 施肥对设施菜地土壤磷累积及淋失潜能的影响. 应用生态学报, 2015, 26(2): 466-472.

[ 4] 孙晓姝, 王立革, 郭珺, 王劲松, 武爱莲, 董二伟, 焦晓燕. 山西曲沃设施蔬菜施肥现状及土壤氮磷累积与分配特征. 生态科学, 2019, $38(6): 149-155$.

[ 5 ] 陆杰, 魏晓平, 张怀志. 面源污染中畜禽有机肥磷的流失形态及其环境效应. 中国人口资源与环境, 2006, 16(5): 130-134.

[ 6 ] Vervoort R W, Radcliffe D E, Cabrera M L, Latimore Jr M. Nutrient losses in surface and subsurface flow from pasture applied poultry litter and composted poultry litter. Nutrient Cycling in Agroecosystems, 1998, 50(1/3): 287-290.

[ 7 ] 颜芳, 王胜涛, 刘涁, 王维瑞, 吴文强, 赵跃. 设施菜田土壤磷素累积特征与风险调控方法. 中国农学通报, 2019, 35(33): 111-115.

[ 8 ] Polis G A, Anderson W B, Holt R D. Toward an integration of landscape and food web ecology : the dynamics of spatially subsidized food webs. Annual Review of Ecology and Systematics, 1997, 28: 289-316.

[ 9 ] Wetzel P R, van der Valk A G, Newman S, Coronado C A, Troxler-Gann T G, Childers D L, Orem W H, Sklar F H. Heterogeneity of phosphorus distribution in a patterned landscape, the Florida Everglades. Plant Ecology, 2009, 200(1): 83-90.

[10］郡学新, 杨慧, 刘旭川, 张盺丽, 吴明. 杭州湾湿地路鸟栖息地土壤养分累积特征. 森林与环境学报, 2019, 39(4): 404-409.

[11] Irick D L, Gu B H, Li Y C, Inglett P W, Frederick P C, Ross M S, Wright A L, Ewe S M L. Wading bird guano enrichment of soil nutrients in tree islands of the Florida Everglades. Science of the Total Environment, 2015, 532: 40-47.

[12] Otero X L, De La Peña-Lastra S, Pérez-Alberti A, Ferreira T O, Huerta-Diaz M A. Seabird colonies as important global drivers in the nitrogen and phosphorus cycles. Nature Communications, 2018, 9(1): 246.

[13] Vizzini S, Signa G, Mazzola A. Guano-derived nutrient subsidies drive food web structure in coastal ponds. PLoS One, 2016, 11(3) : e151018.

[14] 方凤满, 武慧君, 姚有如, 林跃胜, 何成, 吴明宏, 匡盈. 鸟粪对同里湿地公园土壤重金属及其形态的影响. 生态学报, 2018, 38(8): 2925-2933.

[15］鲁如坤. 土壤农业化学分析方法. 北京: 中国农业科技出版社, 2000.

[16] Cross A F, Schlesinger W H. A literature review and evaluation of the. Hedley fractionation: applications to the biogeochemical cycle of soil phosphorus in natural ecosystems. Geoderma, 1995, 64(3/4): 197-214.

[17] Kassila J, Hasnaoui M, Yahyaoui A. Sequential extractions of inorganic and org-Phosphate from fish pond sediments (Deroua station, Beni Mellal, Morocco) by different fractionation methods. Hydrobiologia, 2000, 431(1) : 51-58.

[18] Yu S, He Z L, Stoffella P J, Calvert D V, Yang X E, Banks D J, Baligar V C. Surface runoff phosphorus (P) loss in relation to phosphatase activity and soil P fractions in Florida sandy soils under citrus production. Soil Biology and Biochemistry, 2006, 38(3) : 619-628. 
[19] 宋祖光, 高效江, 张驰. 杭州湾潮滩表层沉积物中磷的分布、赋存形态及生态意义. 生态学杂志, 2007, 26(6) : 853-858.

[20］黄昌勇. 土壤学. 北京: 中国农业出版社, 2000.

[21] 吴明, 邵学新, 胡锋, 蒋科毅. 围层对杭州湾南岸滨海湿地土壤养分分布的影响. 土壤, 2008, 40(5): 760-764.

[22] 刘毅, 陈吉宁. 中国磷循环系统的物质流分析. 中国环境科学, 2006, 26(2):238-242.

[23] 汪涛, 杨元合, 马文红. 中国土壤磷库的大小、分布及其影响因素. 北京大学学报: 自然科学版, 2008, 44(6): 945-952.

[24] 金晓丹, 吴吴, 陈志明, 宋红军, 何义亮. 长江河口水库沉积物磷形态、吸附和释放特性. 环境科学, 2015, 36(2) : 448-456.

[25] 杨士瑛, 国守华. 杭州湾区的气候特征分析. 东海海洋, 1985, 3(4) : 12-22.

[26] 崔虎, 王莉霞, 欧洋, 阎百兴, 韩露, 李迎新. 湿地生态系统磷迁移转化机制研究进展. 水生态学杂志, 2020, 41(2): 105-112.

[27] 安婉丽, 高灯州, 刘晴晴, 王志萍, 陈蓄, 曾从盛. 互花米草人侵对闽江口湿地土壤磷形态及释放风险的影响. 水土保持学报, 2016, 30 (6) : 214-219.

[28] Ziółek M, Melke J. The impact of seabirds on the content of various forms of phosphorus in organic soils of the Bellsund coast, western Spitsbergen. Polar Research, 2014, 33(1) : 19986.

[29] 邵学新, 吴明. 杭州湾潮滩湿地磷素截留效应研究//湖泊湿地与绿色发展——第五届中国湖泊论坛论文集. 长春: 吉林人民出版 社, 2015.

[30］孙海栓, 吕乐福, 刘春生, 盖国胜, 杨玉芬, 何振全. 不同形态磷肥的径流流失特征及其效应. 水土保持学报, 2012, 26(4): 90-93.

[31] Sharpley A, Moyer B. Phosphorus forms in manure and compost and their release during simulated rainfall. Journal of Environmental Quality, 2000, $29(5): 1462-1469$. 